\title{
Analisis Penggunaan Kembali Map Rekam Medis dalam Upaya Memperoleh Efisiensi Biaya di Siloam Hospitals Surabaya
}

\author{
Tri Murni $\mathrm{M}^{1}$, Ina Suhartina ${ }^{2}$, Fransiskus, $\mathrm{W}^{3}$ \\ Sekolah Tinggi Ilmu Administrasi Malang1,2,3 \\ inasuhartina57@gmail.com²
}

\begin{abstract}
ABSTRAK
Latar Belakang: Rekam medis inaktif adalah berkas yang tersimpan paling tidak selama 5 tahun di unit kerja rekam medis terhitung sejak tanggal terakhir pasien tersebut di layani pada sarana pelayanan kesehatan atau telah 5 tahun pasca pasien meninggal dunia. Terdapat beberapa tahapan dalam rekam medis inaktif yaitu di mulai dari pemilahan dan pemindahan dari rak aktif ke rak inaktif. Berlanjut kemudian pada pemilahan berkas yang bisa dimusnahkan, proses alih media, dan pemusnahan itu sendiri. Proses rekam medis inaktif menghasilkan limbah kertas yang akan di musnahkan. Peneliti melihat bahwa limbah kertas tersebut sebenarnya masih dapat digunakan kembali (recycle). Untuk mendaur ulang limbah kertas agar dapat dipergunakan kembali, peneliti memiliki gagasan yang disebut map Re-Use.

Tujuan: Penelitian ini bertujuan untuk menganalisis penggunaan kembali map rekam medis inaktif. Metode: Penelitian ini merupakan penelitian kualitatif deskriptif, peneliti akan memaparkan secara deskriptif hasil analisis penggunaan map Re-Use. Selain itu peneliti juga akan memaparkan hasil estimasi pengeluaran rumah sakit setelah menggunakan map Re-Use.

Hasil: Dari data yang berasal dari bagian pengadaan Siloam Hospitals Surabaya, pada tahun 2016 dikeluarkan biaya sebanyak Rp. 92.875.000,00 untuk pengadaan map baru Siloam Hospitals Surabaya dimana $81 \%$ dari pengeluaran rutin rekam medis. Dengan menggunakan map re-use, maka diperkirakan terjadi efisiensi biaya per bulannya, sebesar Rp. 7.673.333,00. Dengan efisiensi ini, terpecahkan juga masalah ketidaktersediaan tenaga serta didapatkan beberapa manfaat lain, seperti : retensi berjalan, efisiensi pengeluaran biaya, tempat penyimpanan lebih lega dan mengurangi pencemaran lingkungan.

Kesimpulan: Berdasarkan hasil penelitian yang dilakukan, peneliti menyimpulkan bahwa penggunaan map Re-Use dapat meningkatkan efisiensi biaya operasional di unit rekam medis, sehingga biaya operasional Siloam Hospitals Surabaya dapat berkurang.
\end{abstract}

Kata Kunci: Map, Rekam Medis, Rumah Sakit, Map Re-Use

\begin{abstract}
Background: Inactive medical records are files that have been kept for at least 5 years in the medical record work unit since the last date the patient is served at the health services facility or 5 years after death. There are several stages in inactive medical records; it begins from sorting and moving from active shelves to inactive shelves. Then, there will be sorting of files that can be destroyed, the process of transferring the media, and destroying process. This process of inactive medical records produces waste paper that will be destroyed. This waste paper can still be used if it is recycled. Re-Use Folder is invented to recycle paper waste so that it can be reused.

Objective: This study aims to analyze the medical record folder that can be reused.

Method: This research will use descriptive results of the analysis of the use of the Re-Use Folder and to explain the results of estimated hospital expenses after using the Re-Use Folder.

Results: Siloam Hospitals Surabaya spent Rp. 92,875,000.00 (81\%) of routine medical records in 2016. It is expected to reduce cost after using Re-Use Folder per month to be Rp. 7,673,333.00. Thus the problem of unavailability of human resource will also be solved. So that several benefits will obtained, such as: running retention, cost efficiency, larger storage, and reduces environmental pollution.

Conclusion: Based on the results of the research conducted, the use of the Re-Use Folder can improve the efficiency of the production process so that production costs can be reduced.
\end{abstract}

Key words: Files, Medical Records, hospital, Re-Use Map 


\section{PENDAHULUAN}

Masalah kesehatan saat ini menjelma menjadi salah satu kebutuhan primer bagi masyarakat, kebutuhan akan jasa layanan kesehatan yang memadai telah menjadi syarat utama (Suprianto, 2010). Rumah sakit sebagai lembaga jasa layanan kesehatan, sebagai institusi pelayanan kesehatan. Karena itu perlu pemikiran yang tepat yang berkaitan dengan efisiensi dan efektivitas pelayanan sekaligus mampu memberikan pelayanan yang dapat memuaskan pelanggan, pemberi layanan dan pemilik rumah sakit.

Rumah sakit merupakan lembaga penyedia jasa layanan kesehatan dituntut untuk bersikap proaktif dan memberikan pelayanan yang maksimal dan berkualitas untuk konsumenya (Karassavidou.et.all, 2008). Dengan memahami persepsi konsumen terkait dengan pelayanan di rumah sakit serta menerapkan sesuai harapan konsumen, rumah sakit akan mampu bertahan dan memenangkan persaingan di era globalisasi saat ini. Rumah sakit sebagai salah satu subsistem pelayanan kesehatan menyelenggarakan dua jenis pelayanan untuk masyarakat yaitu pelayanan kesehatan masyarakat dan pelayanan administrasi kesehatan. Pelayanan kesehatan masyarakat mencakup pelayanan medik, pelayanan penunjang medik, rehabilitas medik dan pelayanan perawatan. Pelayanan tersebut dilaksanakan melalui unit gawat darurat, unit rawat jalan dan unit rawat inap. Dalam perkembangannya, pelayanan rumah sakit tidak terlepas dari pembangunan ekonomi masyarakat.

Perkembangan ini terlihat pada bergesernya fungsi klasik rumah sakit yang pada awalnya hanya memberi pelayanan yang berwujud penyembuhan (kuratif) kepada pasien. Karena ilmu pengetahuan yang semakin berkembang dengan pesat khususnya teknologi kedokteran, pelayanan kesehatan sekarang tidak saja bersifat kuratif (penyembuhan) tetapi juga pemulihan (rehabilitatif). Keduanya dilaksanakan secara terorganisir melalui upaya publikasi kesehatan (promotif) serta upaya pencegahan (preventif). (Ranjbar.et.all, 2010)
Untuk mendapatkan keunggulan dalam era persaingan global, rumah sakit dituntut mampu menyajikan pelayanan berkualitas dengan harga yang terjangkau serta bersaing dengan rumah sakit yang lain. Tujuan utama rumah sakit dalam menyajikan pelayanan berkualitas adalah tercapainya kepuasan pasien yang ditandai dengan turunya angka keluhan (complain) dari pasien, sehingga menunjukkan pergerakan pertumbuhan perusahaan (rumah sakit) yang tinggi (Andermann.et.all, 2011). Rumah sakit yang merupakan badan usaha dibidang jasa mempunyai tujuan tersendiri sama seperti badan usaha yang lainnya. Produk utama dari rumah sakit adalah pelayanan pada pasien dan sasaran utamanya adalah perawatan dan pengobatan serta kesehatan pada penderita sakit.

Efisiensi pada dasarnya adalah salah satu dari kinerja sebuah organisasi. Kemampuan menghasilkan output yang tinggi dengan input yang ada adalah merupakan ukuran kinerja yang diharapkan. Pada saat pengukuran efisiensi dilakukan, rumah sakit diharapkan pada kondisi bagaimana meraup tingkat input yang minimum dengan tingkat output tertentu. Disisi lain bukan hanya kebijakan pemerintah saja yang dijadikan suatu rumah sakit sebagai bahan pertimbangan dalam memaksimalkan kinerjanya tetapi dewasa ini persaingan antar rumah sakit semakin ketat maka seyogyanya rumah sakit harus memaksimalkan kinerjanya agar dapat bersaing dengan rumah sakit-rumah sakit yang lain, sehingga efisiensi operasional rumah sakit utamanya yang menekan pada rasionalisasi biaya dan efektivitas unit usaha rumah sakit sangat dibutuhkan untuk menunjang persaingan tersebut (Rostami \& Ghahramantan, 2010).

Dari uraian di atas tampak bahwa rumah sakit mengemban tugas yang berat. Di satu sisi dituntut memberi pelayanan yang bermutu yang dapat memuaskan konsumennya. Di sisi yang lain berpraktik secara efektif dan efisien dalam segala hal juga memerlukan perhatian khusus.

Siloam Hospitals Surabaya, yang merupakan salah satu penyedia jasa layanan kesehatan swasta, dimana 
merupakan suatu isntitusi yang harus membiayai semua biaya operasional secara mandiri, dituntut untuk secara serius memikirkan mengenai efisiensi biaya ini. Kenaikan biaya karena inflasi, kenaikan UMR, banyak pasien yang beralih ke BPJS, meningkatnya persaingan antar RS, pengembangan grup rumah sakit menyebabkan efisiensi biaya ini menjadi hal yang sangat penting, bagi kelangsungan operasional rumah sakit.

Bagian rekam medis, merupakan salah satu bagian dengan biaya operasional dengan jenis "stasionery" yang cukup tinggi. Ruang kerja yang harus cukup luas, pengadaan rak penyimpanan yang tidak murah, alat alat tehnologi pendukung, memerlukan investasi yang tidak sedikit. Belum lagi kiranya biaya operasional barang rutin seperti formulir dan pencetakan map berkas Siloam Hospitals Surabaya, merupakan porsi terbesar dari pengeluaran di bagian rekam medis, diluar gaji pegawai.

Dari data yang didapatkan dari bagian pengadaan di Siloam Hospitals Surabaya, pengeluaran terbanyak adalah untuk pencetakan yaitu pengadaan map atau sampul berkas rekam medis. Tahun 2016 didapatkan pengeluaran sebesar $\mathrm{Rp}$. 92.875.000,00 atau $81 \%$ dari pengeluaran rutin bagian rekam medis berasal dari pengadaan map rekam medis. Di sisi lain retensi dan pemusnahan rekam medis rekam medis, meninggalkan limbah, salah satunya adalah map berkas rekam medis. Masalah lainya adalah tenaga khusus untuk melakukan retensi, alih media dan pemusnahan tidak tersedia. Kondisi map rekam medis yang masih cukup bagus dan layak untuk bisa digunakan lagi, mendorong penulis untuk melakukan studi berapa penghematan yang dapat dilakukan, dan apakah penghematan tersebut cukup besar sehingga hasil dari penghematan tersebut, dapat digunakan untuk membayar upah petugas untuk melakukan tugas retensi, alih media, dan pendaurulangan map berkas rekam medis agar bisa digunakan lagi.

\section{Kajian Literature \\ Rumah Sakit}

Berdasarkan undang-undang No. 44 Tahun 2009 tentang rumah sakit, yang dimaksudkan dengan rumah sakit adalah institusi pelayanan kesehatan yang menyelenggarakan pelayanan kesehatan perorangan secara paripurna yang menyediakan pelayanan rawat inap, rawat jalan, dan gawat darurat.

Menurut Permenkes No. 147 tahun 2010 tentang perizinan rumah sakit, "Rumah sakit adalah institusi pelayanan kesehatan yang menyelenggarakan pelayanan kesehatan perorangan secara paripurna yang menyediakan pelayanan rawat jalan, rawat inap, dan rawat darurat"

Menurut Milton Roemer dan Friedman dalam bukunya Doctors in hospitals yang dikutip oleh Suprianto, (2010) fungsi rumah sakit adalah :

a. Harus ada unit pelayanan rawat inap dengan fasilitas diagnosa serta terapeutiknya.

b. Harus tersedianya pelayanan rawat jalan.

c. Rumah Sakit memiliki kewajiban untuk melakukan pendidikan pelatihan bagi elemen rumah sakit.

d. Rumah sakit harus melakukan penelitian dibidang kedokteran dan kesehatan.

e. Bertanggung jawab untuk program pencegahan penyakit dan penyuluhan kesehatan bagi populasi di sekitarnya.

\section{Rekam Medis}

Rekam Medis merupakan dokumen yang berisikan catatan dan dokumen terkait tentang identitas pasien, pemeriksaan, pengobatan, tindakan dan pelayanan lain yang sudah dilakukan kepada pasien (Permenkes 269, tahun 2008). Sedangkan menurut Butt (2010) Rekam Medis adalah fakta-fakta atau bukti kondisi pasien, riwayat penyakit dan pengobatan masa lalu serta saat ini yang di tulis oleh profesi kesehatan yang memberikan pelayanan kepada pasien tersebut.

Tujuan rekam medis adalah membantu secara aktif tercapainya tertib 
administrasi sebagai implementasi dari upaya peningkatan pelayanan kesehatan di rumah sakit. Tanpa didukung suatu sistem pengelolaan rekam medis yang baik dan benar, tidak akan tercipta tertib administrasi rumah sakit sebagaimana yang diharapkan. Sedangkan tertib administrasi merupakan salah satu faktor yang menentukan di dalam upaya pelayanan kesehatan di rumah sakit. (Permenkes 269, tahun 2008).

Adapun kegunaan dari rekam medis dapat di lihat dari beberapa aspek yang disingkat dengan ALFRED PH MP (Hatta.dkk, 2009)

a. Aspek Administrasi (Administrasion): Di dalam berkas rekam medis mempunyai nilai administrasi, karena isinya menyangkut tindakan berdasarkan wewenang dan tanggung jawab sebagai tenaga medis dan paramedik dalam mencapai tujuan pelayanan kesehatan.

b. Aspek Hukum (Legal): Suatu berkas rekam medis mempunyai nilai hukum,karena isinya menyangkut masalah adanya jaminan kepastian hukum atas dasar keadilan, dalam rangka usaha menegakkan hukum serta penyediaan bahan sebagai tanda bukti untuk menegakkan keadilan, Rekam Medis adalah milik Dokter dan Rumah Sakit sedangkan isinya terdiri dari Identitas Pasien, Pemeriksaan, Pengobatan, Tindakan dan Pelayanan lain yang telah di berikan kepada pasien adalah sebagai informasi yang dapat di miliki oleh pasien sesuaidengan peraturan dan perundang-undangan yang berlaku (UU Praktik Kedokteran RI No.29 Tahun 2009 Pasal 46 ayat (1), penjelasan).

c. Aspek Keuangan (Financial): Suatu berkas rekam medis mempunyai nilai uang, karena isinya mengandung data/informasi yang dapat di pergunakan sebagai aspek keuangan.

d. Aspek Penelitian (Research): Suatu berkas rekam medis mempunyai nilai penelitian karena isinya menyangkut data dan informasi yang dapat dipergunakan sebagai aspek pendukung penelitian dan pengembangan ilmu pengetahuan di bidang kesehatan.

e. Aspek Pendidikan (Education) : Suatu berkas rekam medis mempunyai nilai pendidikan, karena isinya menyangkut data/informasi tentang perkembangan kronologis dan kegiatan pelayanan medis yang di berikan kepada pasien, informasi tersebut dapat di pergunakan sebagai bahan/referensi pengajaran di bidang profesi pendidikan kesehatan.

f. Aspek Dokumentasi (Documentation) : Suatu berkas rekam medis mempunyai nilai dokumentasi, karena isinya menyangkut sumber ingatan yang harus di dokumentasikan dan di pakai sebagai bahan pertanggung jawaban dan laporan rumah sakit.

g. Public Health : Suatu berkas rekam medis dapat di gunakan sebagai bahan untuk memprediksi atau mengidentifikasi penyebaran penyakit yang ada sekarang dan masa yang akan datang serta untuk meningkatkan derajat kesehatan nasional atau dunia.

h. Marketing Planning : suatu berkas rekam medis dapat di gunakan sebagai dasar pengambilan keputusan dan pengembangan pemasaran dengan mempromosikan pelayanan yang ada.

\section{Retensi dan Pemusnahan}

Dr. Rano dari Ranocenter, (2014) menjelaskan tentang apa itu retensi. Retensi berarti "menyimpan". Jadi sistem retensi adalah sistem yang mengatur jangka waktu penyimpanan berkas rekam medis. Lebih lanjut Dr. Rano memaparkan tahapan retensi sebagai berikut:

Penyusutan rekam medis adalah suatu kegiatan pengurangan berkas rekam medis dari rak penyimpanan dengan cara;

1. Memindahkan berkas rekam medis inaktif dari rak file aktif ke rak file inaktif dengan cara memilah pada rak file penyimpanan sesuai dengan tahun kunjungan.

2. Memikrofilmisasi berkas rekam medis in aktif sesuai ketentuan yang berlaku. 
3. Memusnahkan berkas rekam medis yang telah di mikrofilm dengan cara tertentu sesuai ketentuan yang berlaku.

4. Dengan melakukan "scaner/pemindai" pada berkas rekam medis

Pemusnahan adalah suatu proses kegiatan penghancuran fisik arsip rekam medis yang sudah berakhir fungsi dan nilai gunanya. Penghancuran harus di lakukan secara total dengan cara membakar sampai habis, mencacah atau di daur ulang sehingga tidak bisa lagi di kenal isi maupun bentuknya. Prosedur pemusnahan umumnya terdiri dari langkah-langkah (Wijaya, 2013):

1. Seleksi.

2. Pembuatan daftar jenis arsip yang di musnahkan.

3. Pembuatan berita acara pemusnahan.

4. Pelaksanaan pemusnahan dengan saksi-saksi.

Daftar pemusnahan berisikan jenis arsip yang dimusnahkan dan jumlah lembarnya, serta periode tahun dari arsip yang di musnahkan. Pemusnahan di laksanakan oleh penanggung jawab kearsipan dan 2 orang saksi dari unit kerja lain. Setelah pemusnahan selesai di laksanakan, maka berita acara dan daftar telaah rekam medis yang dimusnahkan (Hatta.dkk, 2009).

\section{Efisiensi Biaya}

Efisiensi biaya merupakan suatu upaya mengurangi biaya aktivitas organisasi. Maknanya tidak hanya terbatas pengurangan biaya aktivitas saja, tetapi dilihat juga dari aspek sasarannnya, yang dikenal dengan pengendalian biaya (cost containment). Cost containment adalah aktivitas pengendalian biaya pada aktivitas pelayanan secara tidak langsung mempengaruhi perawatan pasien. aktivitas pengendalian biaya difokuskan pada aktivitas yang tidak mempengaruhi langsung perawatan pasien. (Suprianto, 2010)

Menurut Meriyanti (2013), efisiensi adalah suatu ukuran keberhasilan yang dinilai dari besarnya sumber daya yang dikorbankan untuk memperoleh hasil tertentu. Perusahaan yang besar dengan jenis kegiatan yang beragam memiliki pengeluaran biaya yang tidak sedikit. Jika dibiarkan, pengeluaran tersebut dapat berdampak pada penurunan laba yang dihasilkan perusahaan. Oleh karena itu perlu dilakukan efisiensi biaya dalam perusahaan untuk menekan pengeluaranpengeluaran yang tidak perlu, agar tidak terjadi pemborosan biaya. Ada beberapa hal yang harus dilakukan oleh perusahaan untuk melaksanakan efisiensi biaya, yaitu di antaranya:

1. Melakukan efisiensi biaya produksi

2. Meningkatkan efisiensi dan kinerja tenaga kerja

3. Menetapkan biaya standar

\section{METODE PENELITIAN}

Penelitian ini merupakan penelitian deskriptif kualitatif, menurut Creswell (2010) penelitian deskriptif kualitatif adalah prosedur penelitian yang menghasilkan data deskriptif berupa katakata tertulis atau lisan dari fenomenafenomena yang diamati. Dengan pendekatan deskriptif kualitatif dapat dideskripsikan proses penggunaan map Re-Use dalam upaya efisiensi biaya operasional rumah sakit.

Penelitian ini berlokasi di Siloam Hospitals Surabaya, dengan fokus penelitian pada proses pemanfaatan kembali map rekam medis, kemudian efeknya terhadap efisiensi biaya pegeluaran di Siolam Hospitals Surabaya setiap bulanya. Untuk itu peneliti membutuhkan data sekunder berupa laporan pemakaian barang rutin dari bagian pengadaan (Material Management Departement) dan data jumlah pasien baru dari tiap unit pelayanan departemen rekam medis. Data tersebut didapat dengan cara mengambil data pemakaian map rekam medis pertahun, dan jumlah pasien baru dalam 3 bulan terakhir. Data tersebut berasal dari unit pelayanan rawat jalan, rawat inap, UGD, fisioterapi, daycare, dan hemodialisa.

Selanjutnya data akan analisis secara deskriptif. Kebutuhan biaya untuk pasien baru akan dihitung dan hasilnya akan dibandingkan antara biaya prngadaan map baru dengan map Re-Use. Perbandingan yang dilakukan meliputi perhitungan biaya sebelum menggunakan map Re-Use dan sesudah menggunakan 
map Re-Use. Selisih biaya tersebut akan menjadi besaran nilai efsiensi biaya.

\section{HASIL PENELITIAN DAN PEMBAHASAN}

Sebelum membahas mengenai proses pengunaan map ReUSe, akan dipaparkan kebijakan SOP retensi sampai pada pemusnahan kertas di Siolam Hospitals Surabaya sebagai berikut :

1. Rekam medis dinyatakan inaktif jika melewati masa 5 tahun dari kunjungan terakhir.

2. Rekam medis yang sudah inaktif dilakukan pemusnahan, kecuali resume medis dan persetujuan tindakan medis harus disimpan dalam jangka 10 tahun terhitung dari tanggal dibuatnya kedua dokumen tersebut. pada setiap pemusnahan rekam medis dibuat berita acara pemusnahan rekam medis.

3. Pemusnahan rekam medis inaktif dapat dikerjakan oleh pihak ketiga yang diatur dengan perjanjian secara tertulis untuk mejaga kerahasiaan data-data pasien.

4. Pada rekam medis inaktif juga dilakukan alih media, yang meliputi
a. Pendaftaran Pasien baru
b. Resume medis Pasien pulang
c. Persetujuan tindakan medis/informed consent (bila ada)
d. Laporan Operasi
e. Hasil pemeriksaan Patologi anatomi 9bila ada)
f. Surat kematian dan kelahiran (bila ada)
g. Pengisian data untuk surat keterangan lahir (bila ada)
h. Permintaan Perubahan data pasien (bila ada)

Sedangkan Petunjuk tehnis (SOP) retensi dan alih media adalah sebagai berikut

1. Berkas rekam medis yang diretensi adalah berkas rekam medis pasien, yang telah berumur lebih dari 5 tahun sejak kunjungan terakhir pasien

2. Setelah selesai, pada modul rekam medis, beri tanda ** didepan kolom nama pasien. Contoh : **Tukul Arwana, Tn

Hal ini untuk menandakan dan memudahkan petugas rekam medis, bahwa rekam medisnya telah disimpan pada rak inaktif dan siap dimusnahkan

3. Form form rekam medis yang dialih mediakan adalah :

a. Isian identitas pasien.

b. Form integrated note OPD (rawat jalan).

c. form AE (unit Gawat Darurat).

d. Form fisioterapi

Untuk pasien rawat inap, terdapat petunjuk teknis sesuai kebijakan sebagai berikut:.

4. Lakukan alih media terhadap form form tersebut.

5. Masukkan pada daftar pemusnahan.

6. Bila pasien berobat lagi, nomor lama tetap dipakai, hanya diberi map baru, dengan keterangan berkas telah dialihmediakan. Tanda ${ }^{* *}$ dihapus dari data pasien.

Proses penggunaan map ReUse akan dilakukan pada saat proses alih media dan identifikasi berkas yang akan dimusnahkan. Proses penggunaan map ReUse terdiri dari beberapa tahapan sebagai berikut :

1. Dilakukan pemilahan map yang masih layak untuk digunakan kembali.

2. Dilakukan pembersihan map dari formulir formulir rekam medis yang masih ada atau menempel.

3. Dilakukan penempelan stiker putih polos, satu untuk menutupi nama pasien sebelumnya. Kedua, untuk menutupi nomor rekam medis sebelumnya. Setelah itu maka berkas map rekam medis, dapat digunakan kembali, untuk pasien baru.yang akan berobat.

Map ReUse dapat digunakan untuk pasien rawat jalan, rawat inap, fisioterapi, hemodilisa, kecuali untuk pasien dari Departemen Emergency atau UGD. Hal ini dikarenakan pada sistem UGD, setiap pasien yang datang pasti memerlukan 1 lembar pemeriksaan UGD. Untuk menghindari hilangnya lembar tersebut, maka lembar pemeriksaan UGD untuk pasien baru, dijadikan satu dengan map rekam medisnya. Untuk pasien baru, maka isian identitas pasien baru dan dijadikan satu didalam map rekam medis dan diberikan ke pasien atau pendaftar 
untuk diisikan detail identitas pasien. Karena dikawatirkan adanya komentar, pandangan negatif, bahkan publikasi yang merugikan, bila pihak pasien mengetahui bahwa rumah sakit menggunakan map hasil proses penggunaan kembali (ReUse), untuk itu khusus untuk berkas Map rekam medis pasien baru di UGD, tetap menggunakan map rekam medis baru.

Setelah meggunakan map ReUse, terjadi penyusutan pengeluaran biaya bulanan di Siolam Hospitals Surabaya. Data yang diperoleh dari bagian Material Management Department atau bagian pengadaan, harga 1 buah map rekam medis tahun 2016 sebesar Rp. 4.500,00. Sepanjang tahun 2016, bagian pengadaan telah membelanjakan sebesar Rp. 92.875.000,00 untuk pengadaan map rekam medis ini. Untuk tahun 2017, harga map rekam medis sebesar Rp. 5.000,00 untuk setiap mapnya.

Bila diasumsikan bahwa map rekam medis digunakan atau diberikan untuk pasien baru, maka berdasarkan data yang didapat dari sistem informasi rumah sakit, data pasien baru adalah sebagai berikut:

Tabel 1. Jumlah Pasien Baru Per Unit Pelayanan, di Siloam Hospitals Surabaya, Bulan Januari - Juni 2017

\begin{tabular}{cccccccc}
\hline $\begin{array}{c}\text { Departemen } \\
\text { Pelayanan }\end{array}$ & 1 & 2 & 3 & 4 & 5 & 6 & $\begin{array}{c}\text { Rata } \\
\text { rata } \\
\text { per } \\
\text { bulan }\end{array}$ \\
\hline Day Care & 23 & 17 & 18 & 16 & 27 & 10 & 19 \\
Fisioterapi & 66 & 54 & 56 & 64 & 62 & 55 & 60 \\
Inpatient & 67 & 62 & 79 & 65 & 91 & 53 & 70 \\
Medical & 304 & 160 & 127 & 121 & 94 & 153 & 160 \\
Check Up & & & & & & & \\
Outpatient & 1362 & 1171 & 1323 & 1203 & 1298 & 1007 & 1227 \\
TOTAL & 1822 & 1464 & 1603 & 1469 & 1572 & 1278 & 1535 \\
& & & & & & &
\end{tabular}

Sumber : Sistem informasi Siloam Hospitals Surabay, 2017

Dari tabel diatas didapatkan pemakaian map baru dari bulan Januari 2017 sampai bulan Juni 2017, sebanyak 9208 berkas rekam medis yang digunakan. Bila dirata rata sebulan sebanyak 1535 berkas. Bila dihitung secara rupiah harga per map, maka didapatkan biaya sebesar. 9208 x Rp. 5000 = Rp. 46.040.000,00 sehingga jika dirata-rata, pengeluaran biaya perbulan untuk pengadaan map rekam medis adalah sebesar Rp.7.673.333.

Ketika proses map ReUse sudah dilakukan, tentu ada biaya yang timbul, biaya tersebut meliputi biaya tetap, biaya variabel dan biaya campuran (Hansen, 2009). Biaya tetap dalam hal ini adalah gaji pegawai yang melakukan proses ReUse. Seangkan biaya variabel dalam hal ini adalah biaya pengadaan stiker penutup. Berdasarkan data sekunder dari bagian pengadaan, 1 lembar stiker ukuran A4 seharga Rp.500,00. Dari tabel dibawah ini dapat diketahui biaya variabel yang dikeluarkan untuk proses reuse 1 buah map rekam medis.

Tabel 2. Perincian Biaya Variabel Dalam Proses Pengunaan Kembali (reuse) Map Rekam Medis, di Siloam Hospitals Surabaya, 2017

\begin{tabular}{|c|c|c|c|}
\hline & $\begin{array}{l}\text { Jumlah } \\
\text { Stiker } \\
\text { potongan/ } \\
\text { lembar A4 }\end{array}$ & $\begin{array}{l}\text { Harga } \\
\text { stiker / } \\
\text { lembar } \\
\text { A4 } \\
\text { (rupiah }\end{array}$ & $\begin{array}{l}\text { Biaya } \\
\text { untuk } \\
\text { map } \\
\text { (Rupiah) }\end{array}$ \\
\hline $\begin{array}{l}\text { Stiker penutup } \\
\text { sampul depan }\end{array}$ & 12 & 500 & 41,6 \\
\hline $\begin{array}{l}\text { Stiker penutup } \\
\text { nomor RM samping }\end{array}$ & 4 & 500 & 125 \\
\hline
\end{tabular}

Sumber : Hasil Penelitian, 2017

Dari tabel diatas, dapatdisimpulkan bahwa untuk proses penggunaan kembali (reuse) map, hanya dibutuhkan biaya sebesar Rp. 167,00 Jika diperhitungkan total dengan biaya pengeluaran untuk tambahan gaji pegawai baru, maka perhitungan dapat dilihat pada tabel berikut :

Tabel 3. Gambaran Rata-rata Total Efisiensi Biaya Per Bulan, Penggunaan Map Rekam Medis reuse, di Siloam Hospital Surabaya, 2017

\begin{tabular}{ll}
\hline \multicolumn{1}{c}{ PERINCIAN } & $\begin{array}{l}\text { Dalam } \\
\text { Rupiah }\end{array}$ \\
\hline a. MAP baru & 7.675 .000 \\
1535 x Rp. 5000,00 & \\
b. MAP bekas yang digunakan & 256.345 \\
kembali & \\
1535 x Rp. 167,00 &
\end{tabular}


Tabel 3. (lanjutan) Gambaran Rata-rata Total Efisiensi Biaya Per Bulan, Penggunaan Map Rekam Medis reuse, di Siloam Hospital Surabaya, 2017

\begin{tabular}{ll}
\hline c. Biaya pegawai (UMR 2017) & $3.296 .212,50$ \\
\hline TOTAL SELISIH $(\mathrm{a}-(\mathrm{b}+\mathrm{c}))$ & $\mathbf{4 . 1 2 2 . 4 4 3}$ \\
\hline
\end{tabular}

Sumber : Hasil Penelitian, 2017

Dari tabel diatas didapatkan gambaran rata rata penghematan sebesar Rp.4.122.443,00 perbulan, atau bila di asumsikan untuk satu tahun maka didapatkan perkiraan penghematan sebesar Rp. 49.469.310,00 per tahunnya. Selain efisiensi dari segi biaya, keuntungan lain dengan melakukan efisiensi ini adalah :

a. Kebutuhan pembiayaan tenaga untuk melakukan proses alih media, retensi dan pemusnahan dapat teratasi.

b. Dengan dilakukan retensi, maka rak akan menjadi lebih longgar/lega, sehingga lebih memudahkan saat proses penjajaran (filling) ataupun saat pengambilan berkas di dalam rak. Sehingga menunjang mutu pelayanan rekam medis dalam hal penyediaan berkas rekam medis.

c. Kapasitas rak penyimpan berkas rekam medis aktif menjadi lebih banyak.

d. Rak penyimpanan menjadi lebih rapi.

\section{KESIMPULAN DAN SARAN}

Berdasarkan hasil penelitian dapat disimpulkan tiga hal sebagai berikut :

1. Proses memanfaatkan kembali (reuse) map rekam medis, dilakukan setelah proses alih media, dengan menutup semua catatan pemilik map sebelumnya dengan menggunakan stiker, dan digunakan untuk semua unit pelayanan, kecuali UGD.

2. Rata rata penggunaan map dalam satu bulannnya sekitar 1535 map rekam medis, dan rata rata biaya untuk pengadaannya sebesar Rp.7.675.000,00

3. Besarnya efisensi bersih (nett) penggunaan map kembali (ReUse) ini dalam 1 bulan berkisar Rp. 4.122.443,00. Dimana sudah diperhitungkan dengan biaya variabel dan biaya untuk gaji/ honor 1 pegawai.

Peneliti juga memiliki beberapa saran terkait hasil penelitian sebagai berikut :
1. Perlu adanya tambahan seorang karyawan untuk melakukan proses map ReUse.

2. Bila kebijakan penambahan tenaga tidak diperbolehkan, maka alokasi dana untuk tambahan satu tenaga, bisa ditawarkan kepada staf rekam medis yang bersedia, dengan perhitungan biaya yang sesuai dengan tabel 3 . Dengan cara ini maka rumah sakit tidak terbebani dengan jumlah tenaga yang makin bertambah, sedangkan bagi staf rekam medis mendapat tambahan penghasilan.

\section{DAFTAR PUSTAKA}

Andermann, A. Gingsburg, L. Norton, P. Arora, N. Bates, D. Wu, A. (2011). Core competencies for patient safety research: a cornerstone for global capacity strengthening. BMJ Qual Saf, Volume 2O(No. 1), 96-101.

Butt, M. \& de R. E. (2010). Private Healthcare quality: applying a SERQUAL model. Int $J$ Health Care Qual Assur, Volume 23(No. 7), 65-73.

Creswell, J. W. (2010). Research Design: Pendekatan Kualitatif, Kuantitatif, dan Mixed. Yogyakarta: PT Pustaka Pelajar.

Hansen, and M. (2009). Managerial Accounting. In Edisi 8. Jakarta: Salemba Empat.

Hatta, G. (2009). Pedoman Manajemen Informasi Kesehatan di Sarana Pelayanan Kesehatan. Jakarta: UIP.

Indradi, R. (2014). Sistem Retensi Rekam Medis. Retrieved from http:/ / ranocenter.weebly.com/blogranocenter/sistem-retensi-rekammedis

Karassavidou, E. (2008). Papadopoulos CT. Health care quality in Greek NHS hospital: No one knows better than patients. In Proceedings of the 11th QMOd Conference on Quality Management and Organizational Development Attaining Sustainability from Organizational Excellence to Sustainable Excellence. Helsingborg, Sweden.

Meriyanti, G. (2013). Analisis efisiensi biaya operasional melalui pengelolaan tunjangan makan dan 
jaminan pemeliharaan kesehatan pada perusahaan outsourcing. Jurnal EMBA Universitas Sam Ratulangi, Volume 1(No. 1), 1-10.

Peraturan Menteri Kesehatan Nomor 147 / MENKES / PER / I / 2010 tentang perizinan rumah sakit. (n.d.). Jakarta: Departemen Kesehatan RI.

Peraturan Menteri Kesehatan Nomor 269 / MENKES / PER / III / tentang rekam medis. (n.d.). Jakarta: Departemen Kesehatan RI.

Ranjbar, EM. Bahrami M. Zare, AH. Nasiri, S. (2010). Gap Analysis between perceptions and expextations of service recipients through SERVQUAL approach in
Yazd, Afshar hospital. Toloo-EBehdasht, Volume 9(No. 29), 75-85.

Rostami H, R. A. G. A. (2010). The viewpoint of nurses about professional relationship between nurses and physicians. Journal of Research Development in Nursing \& Midwifery, Volume 7No. 1), 63-72.

Suprianto. (2010). Manajemen mutu pelayanan kesehatan. In Heat Advocacy. Surabaya.

Undang Undang Republik Indonesia No. 29 Tahun 2009 tentang praktik kedokteran. (n.d.).

Wijaya, L. (2013). Pemusnahan Rekam Medis. Jakarta: Esa Unggul. 